\title{
Creep and Recovery Behavior of Compression Molded Low Density Polyethylene/Cellulose Composites
}

\author{
Martin M. Riara, Abdallah S. Merenga, and Charles M. Migwi \\ Department of Physics, Kenyatta University, P.O. Box 43844, Nairobi, Kenya \\ Correspondence should be addressed to Martin M. Riara; riaramartin@gmail.com
}

Received 15 August 2013; Revised 29 October 2013; Accepted 16 November 2013

Academic Editor: Cornelia Vasile

Copyright ( 2013 Martin M. Riara et al. This is an open access article distributed under the Creative Commons Attribution License, which permits unrestricted use, distribution, and reproduction in any medium, provided the original work is properly cited.

\begin{abstract}
Low density polyethylene (LDPE) is an important industrial material because it is durable, light-weight, easily processed and characteristically inert, but its everyday use is hazardous to the environment. The solution to this seems to consist of incorporation of biopolymers in the structure of LDPE to form composites. Compression molded composites at different cellulose loading were subjected to creep tests at $30,40,50$, and $60^{\circ} \mathrm{C}$. The samples were displaced for 12 minutes and allowed to recover for 12 minutes. Creep behavior of the polymer composites was governed by temperature, time, and cellulose loading. Creep performance decreased with increase in temperature and improved with cellulose loading while creep modulus decreased with increase in time and temperature. Time temperature superposition was used to predict the long time (up to $10^{6} \mathrm{~s}$ ) creep behavior of the samples. William-Landel-Ferry (WLF) model offered a better description of the shift factors based on the short term data that was used to predict the long time behavior of the polymer composites by shifting the curves along the logarithmic time axis. The deformation was dependent on free volume.
\end{abstract}

\section{Introduction}

Creep is the deformation of solid material or viscous liquids under the influence of stress. In polymers, creep occurs by chains untangling and slipping relative to one another, because a polymer consists of long chain-like molecules in a tangled and coiled arrangement. Polymer deformation occurs progressively at a decreasing strain rate until it is constant or zero. Polymeric materials exhibit viscoelastic behavior; they do not exhibit purely elastic (ideal solids) or purely viscous (ideal liquid) behavior but a combination of both viscous and elastic properties in varying amounts. The rate of viscoelastic deformation depends on nature of the material, duration and temperature of exposure, and the magnitude of applied structural load. A typical creep test is performed by applying constant stress and monitoring the strain levels with time.

Mechanical analogs are used to describe viscoelastic behavior of polymers. The simplest of them all is the Hookean spring while the Burgers model offers the best qualitative description of both creeps and strain relaxation behavior of viscoelastic materials [1]. According to this model the response to a constant stress is given by [2]

$$
\varepsilon(t)=\sigma\left\{\frac{1}{E_{1}}+\frac{t}{\eta_{1}}+\frac{1}{E_{2}}\left[1-\exp \left(-\frac{t}{\tau_{2}}\right)\right]\right\},
$$

where $\sigma$ is the applied stress, $\varepsilon$ the strain, $\eta$ the viscosity of the dashpot, $E_{1}$ and $E_{2}$ the spring modulus for the springs in a Burgers model, and $\tau_{2}=\eta_{2} / E_{2}$ the relaxation time.

There are two ways of predicting long time behavior of polymers. The long term behavior can be measured directly (which is time consuming and tedious and has a slow response) or relaxation experiments can be carried out at time $T_{1}$ within experimentally accessible time scales and then repeated at time $T_{2}$ and then the curves at time $T_{2}$ shifted horizontally to the right to give an exact superposition of curves obtained at temperatures $T_{1}$ and $T_{2}$ [3]. According to this principle, creep modulus $E(t, T)$ at temperature $T_{1}$ can 
be related directly to that at $T_{2}$ by using a multiplicative shift factor $a_{T}$ to the time scale $(t)$, namely,

$$
E\left(t, T_{1}\right)=E\left(t \times a_{T}, T_{2}\right)
$$

This superposition manifests itself from the behaviour of molecules. To explain this behaviour equations based on activation energy are commonly used. Such equations include the Arrhenius equation

$$
\tau=\tau_{o} \exp \frac{E_{a}}{k T},
$$

where $\tau_{o}$ is the preexponential factor, $k$ is the Boltzmann constant, and $E_{a}$ is the activation energy, which relates horizontal shift factor $a_{T}$ (parallel to the logarithmic time axis) to temperature. Similarly, the William-Landel-Ferry equation (4) which relates shift in temperature to the time shift is also used:

$$
\log \frac{\tau(T)}{\tau_{g}}=\log a_{T}=-\frac{C_{1}\left(T-T_{o}\right)}{C_{2}+T-T_{o}},
$$

where $a_{T}$ is the shift factor relative to the defining temperature, $T_{o}$, and $C_{1}$ and $C_{2}$ are empirically determined constants. $T$ is the experimental temperature, in ${ }^{\circ} \mathrm{C}$ or $\mathrm{K}$, and $T_{o}$ is the reference temperature, in ${ }^{\circ} \mathrm{C}$ or $\mathrm{K}$. This equation demonstrates the frequency dependence of glass transition temperature.

LDPE is characteristically inert and therefore remains in nature, getting degraded at a very slow rate, estimated in decades. The recalcitrant nature of LDPE results from its high molecular weight, complex three-dimensional structure, and its surface hydrophobicity all of which interfere with its availability to microorganisms. The various approaches for plastic waste disposal, land filling, incineration, and recycling have their own limitations. Recycling will not yield quality products due to heterogeneous nature of the plastics. Besides that, the recycling technologies are still under development. Incineration of plastics will release toxic gases and vapors, which could prove to be a serious health hazard and use of plastic in landfill operations is the least preferred because of space constraints [4]. It is increasingly felt that the best alternative would be improving the biodegradability of these plastics [5].

Blending LDPE with biopolymers inserts hydrophilic groups that lower the surface energy. Consumption of the polar hydrophilic biopolymer causes fracture in the polymer chain and, through the fractures, microorganisms can access the carbon links of polyethylene; the result is the polymer biodegradation [6]. Starch has minimum interference to polymer melting properties and is highly biodegradable, available, and cheap [7]. However, increasing the amount of starch in a polymer matrix causes a serious decrease in mechanical properties, due to poor adhesion between starch and LDPE (due to their difference in polar characteristics and weak structural rigidity of starch) [8]. Cellulose differs fundamentally from starch; it is linear with beta acetal glucosidic linkages while starch is branched with alpha acetal glucosidic linkages. The linear structure and numerous hydrogen bonds
TABLE 1: Masses of LDPE and cellulose, sample notation, and percentage concentrations.

\begin{tabular}{lcccc}
\hline \multicolumn{2}{c}{ Mass (g) } & \multirow{2}{*}{ Sample notation } & \multicolumn{2}{c}{ Concentrations (\%) } \\
LDPE & Cellulose & & LDPE & Cellulose \\
\hline 8 & 0 & P100C0 & 100 & 0 \\
7.6 & 0.4 & P95C05 & 95 & 5 \\
7.2 & 0.8 & P90C10 & 90 & 10 \\
6.8 & 1.2 & P85C15 & 85 & 15 \\
6.4 & 1.6 & P80C20 & 80 & 20 \\
6.0 & 2 & P75C25 & 75 & 25 \\
5.6 & 2.4 & P70C30 & 70 & 30 \\
\hline
\end{tabular}

present in cellulose make it possess rigid microfibrils [9]. However, cellulose is less biodegradable compared to starch due to its slightly higher molecular weight. In essence, the aim of this work was to prepare compression molded $\mathrm{LDPE} /$ cellulose composites, investigate the effect of cellulose concentration creep performance of LDPE reinforced with cellulose, and compare them with neat LDPE.

\section{Materials and Methods}

2.1. Materials Characterization. LDPE grade LL6201 was obtained from Afro Plastics (Kenya) Company, Nairobi. It has a number average molecular weight of about $90000 \mathrm{~g} / \mathrm{mol}$ and density of $0.92 \mathrm{~g} / \mathrm{cm}^{3}$. Cellulose was extracted from dried cell sap of Acacia plants.

2.2. Sample Preparation. A total of $8 \mathrm{~g}$ were used as reference mass to determine the proportions of LDPE and cellulose in the composite. Cellulose concentrations were increased in steps of $5 \%$ starting with $0 \%$. Acacia cell sap was dried at $90^{\circ} \mathrm{C}$ and crushed to a fine powder using a mortar and pestle. The powder was then sieved using a $0.67 \mathrm{~mm}$ sieve to remove any debris. Appropriate quantity, of LDPE granules was heated to $130^{\circ} \mathrm{C}$ for about 8 minutes in the heating chamber. Molten LDPE was then mixed with crushed cellulose in the ratios by mass of $1: 0,7.6: 0.4,7.2: 0.8,6.8: 1.2,6.4: 1.6,6: 2$, and $5.6: 2.4$. Sample notations and corresponding percentage compositions are presented in Table 1.

A screw with a pitch width of about $9 \mathrm{~mm}$ was used for the mixing. During mixing the screw was rotated at a speed of $2970 \mathrm{rpm}$ to obtain optimum dispersion within a constant time span of $60 \mathrm{~s}$. Once a homogeneous composite was attained, the stopper was then removed from the injection hole. Spacers were placed at the edge of the molding chamber and the composite injected into the molding tray by rotating the screw continuously. The composite was then hot pressed vertically down with the hot cover and the mold allowed to cool for 10 minutes to form a block which was then removed from the molding tray. From the block two samples were cut each with dimensions of $25 \mathrm{~mm}$ by $4 \mathrm{~mm}$ by $3 \mathrm{~mm}$.

2.3. Creep Measurement. The creep and recovery behavior of the polymers was studied using DMA 2980 (TA Instruments, New Castle, USA) in a single cantilever mode with a constant 


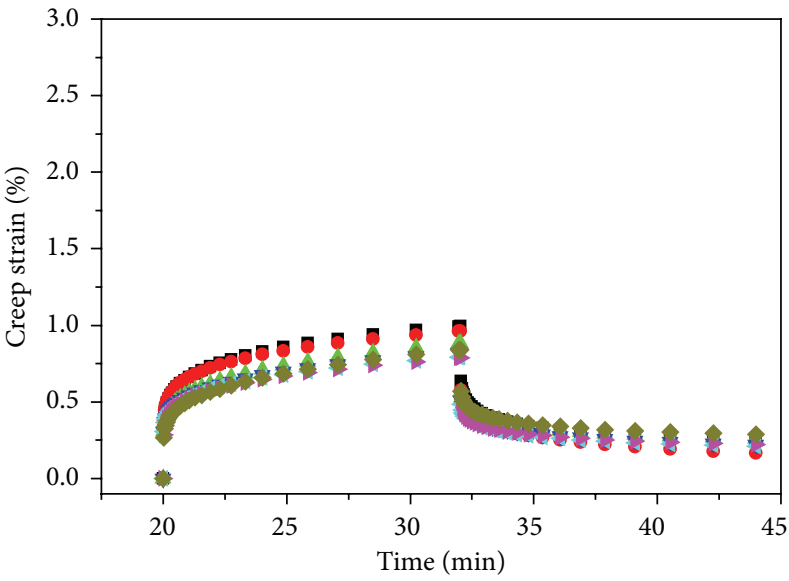

(a)

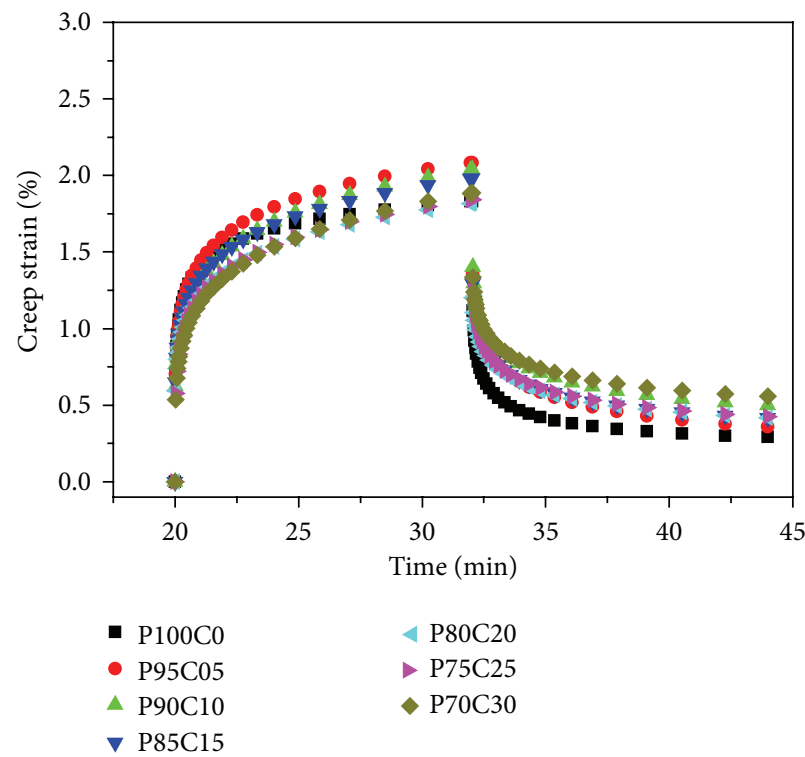

(c)

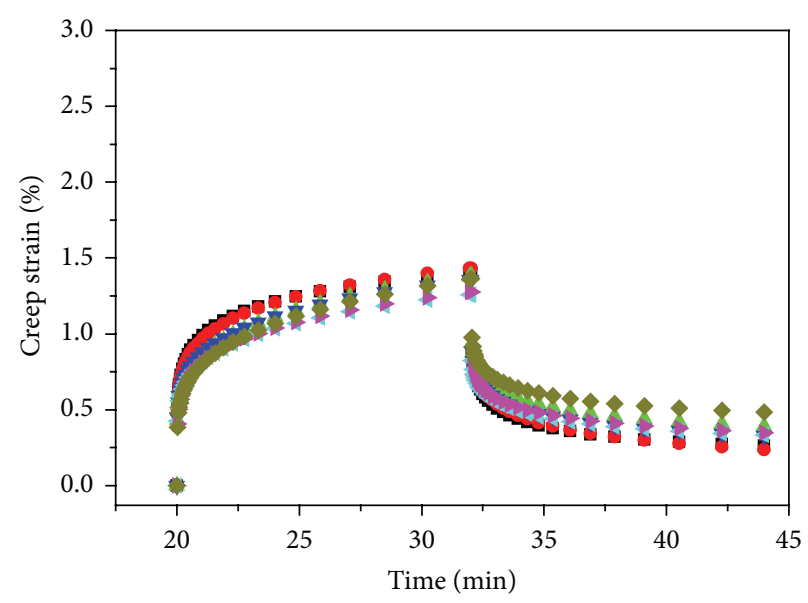

(b)

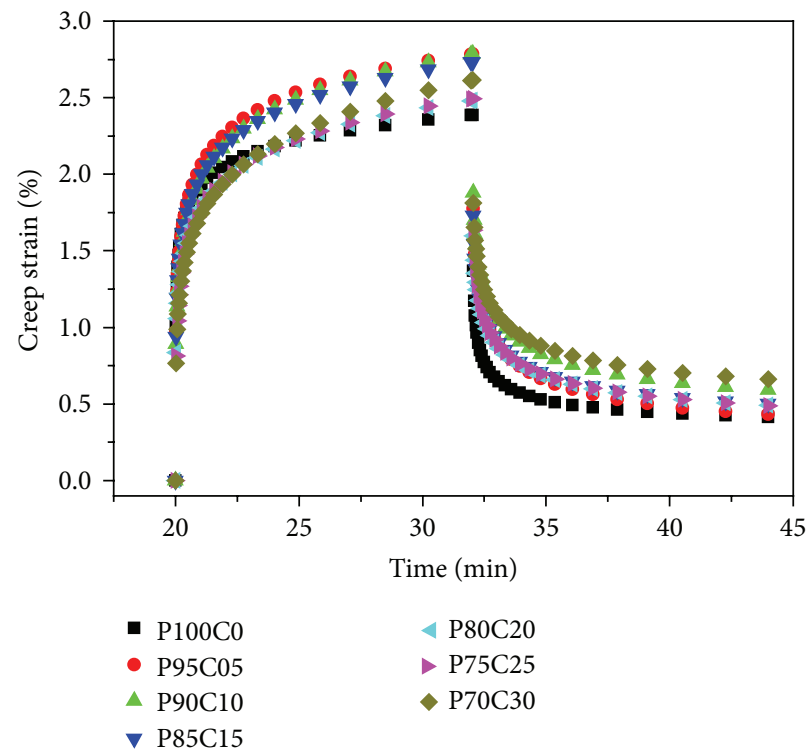

(d)

Figure 1: Percentage creep strain and recovery against time for LDPE/cellulose: composites (a) $30^{\circ} \mathrm{C}$, (b) $40^{\circ} \mathrm{C}$, and (c) $50^{\circ} \mathrm{C}$, (d) $60^{\circ} \mathrm{C}$.

span of 12 minutes. The furnace was set to the desired temperature $\left(30\right.$ to $60^{\circ} \mathrm{C}$ ), the sample was then allowed to equilibrate for 20 minutes, and creep measurements were initiated by setting the machine to displace at $1 \mathrm{MPa}$ at temperatures of $30,40,50$, and $60^{\circ} \mathrm{C}$. The time of application of force was 12 minutes and recovery time of 12 minutes.

\section{Results and Discussion}

3.1. Effect of Cellulose on Percentage Creep Strain of LDPE/Cellulose Composites. Figure 1 displays the strain percentage as a function of time for all composites in four different temperature conditions.

In these curves the creep stages (instantaneous deformation, primary and secondary creeps) can be clearly observed. There is no evidence of tertiary creep, that is, creep rapture, which would require longer time and larger stress. Initially dislocations are generated continually in the primary creep stage. With time, more and more dislocations develop, producing increasing interference with each other's movement, thus causing creep rate to decrease. This dynamic equilibrium sets in secondary creep and the material creeps at a constant rate. As expected \% creep strain increased with increase in temperature in both neat LDPE and its composites. It is apparent that raising temperature from 30 to $60^{\circ} \mathrm{C}$ the peak \% creep strain increased by $160 \%$ approximately for neat LDPE. Thus the value of the \% creep strain towards the temperature change is very sensitive. This is due to the fact that temperature decreases the activation barrier for bond dissociation thus allowing molecular chains to untangle, slip, and reorient more easily.

These results also indicate that \% creep strain of the composites was lower than that of neat LDPE matrix at 30 and $40^{\circ} \mathrm{C}$. Hence at these temperatures, the creep performance 


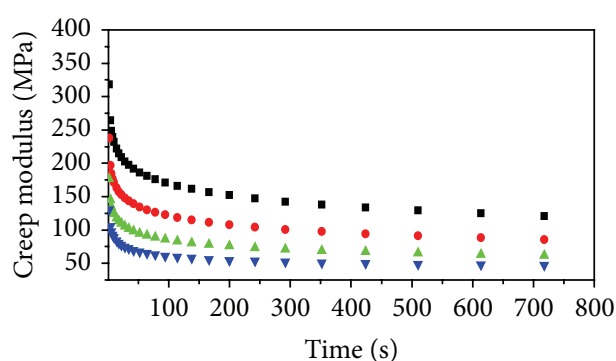

P100C0

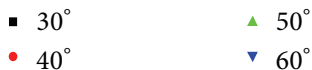

(a)

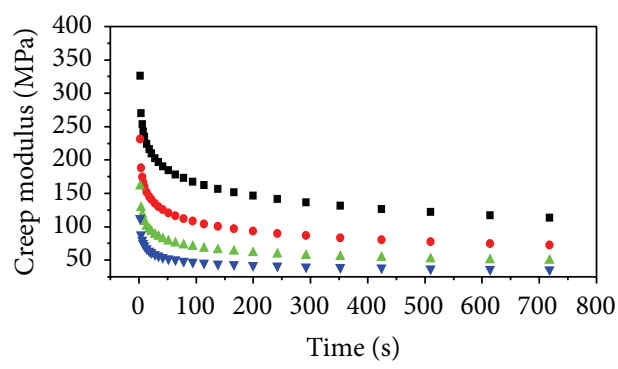

$\mathrm{P} 90 \mathrm{C} 10$

- $30^{\circ}$

- $40^{\circ}$

$\triangle 50^{\circ}$

จ $60^{\circ}$

(c)

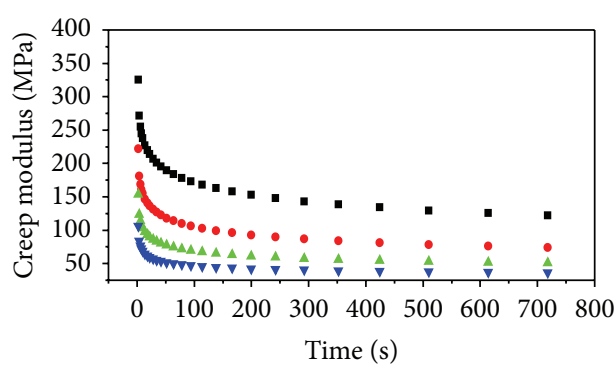

$\mathrm{P} 85 \mathrm{C} 15$

$\begin{array}{ll}-30^{\circ} & \triangle 50^{\circ} \\ \text { - } 40^{\circ} & \checkmark 60^{\circ}\end{array}$

(e)

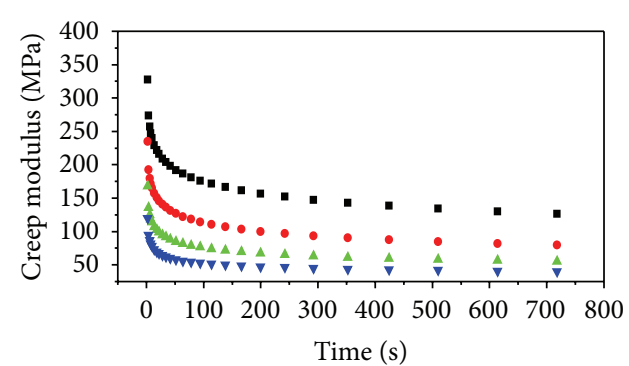

$\mathrm{P} 80 \mathrm{C} 20$

- $30^{\circ} \quad \triangle 50^{\circ}$

- $40^{\circ}$

(b)

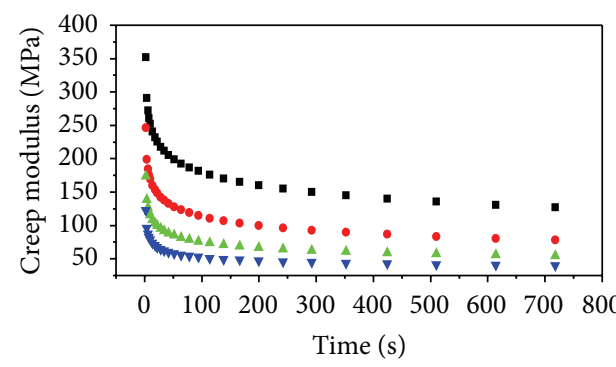

$\mathrm{P} 75 \mathrm{C} 25$

- $30^{\circ} \triangle 50^{\circ}$

- $40^{\circ}$

> $60^{\circ}$

(d)

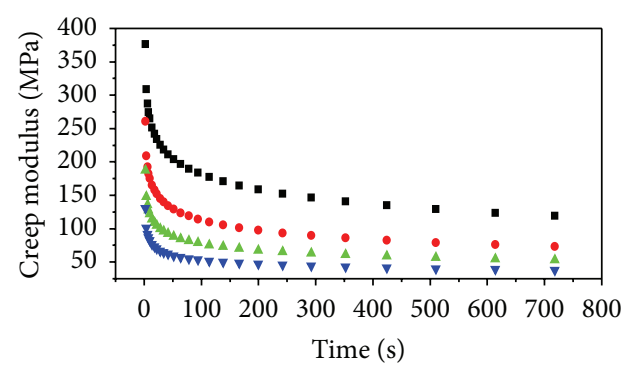

P70C30NF

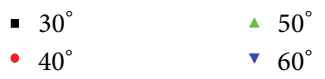

(f)

FIGURE 2: Creep modulus versus time for LDPE/cellulose composites.

of the material improved with cellulose loading. At higher temperatures, addition of $5 \%$ cellulose rapidly reduces the creep performance of the material, but further addition of cellulose improves the creep performance of the material to a limit of $25 \%$ cellulose beyond which the performance decreases. This can be explained as follows: at 5\% cellulose loading, the microfibrils are sparsely distributed. Due to the high temperatures, attraction of the $\mathrm{OH}$ groups is minimal. Because of the incompatibility of cellulose and the nonpolar LDPE, the regions occupied by cellulose behave like regions with defects, hence potential sites for crack initiation and propagation. At higher cellulose concentrations, attraction of the microfibrils is significant and the structure is reinforced. Resistance to creep strain for cellulose composites is very high because cellulose resists slippage, reorientation, and motion of the polymer chains in the composite [10]. The hydrogen bonding interactions between cellulose chains cause a stiffening effect on the polymer matrix adjacent to the filler-particle interphase. At 30\% cellulose concentrations, the $\%$ creep strain increases. This is probably because the filler particles begin to form aggregates. These aggregates are regions of stress concentration that require less energy to initiate or propagate a crack and, therefore, sites for potential composite fractures. 


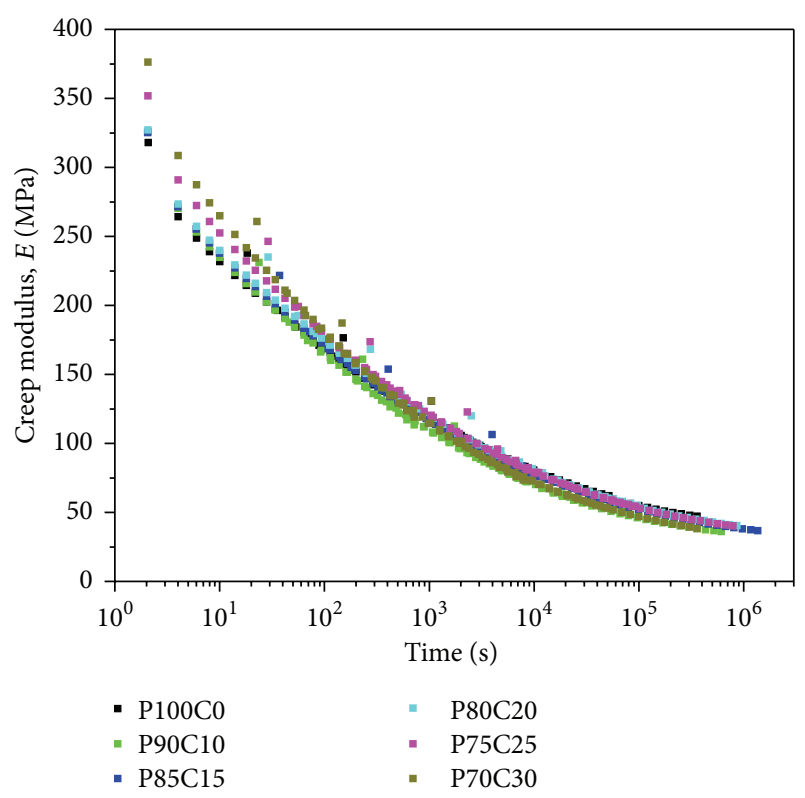

Figure 3: Master curves showing creep modulus as a function of time.

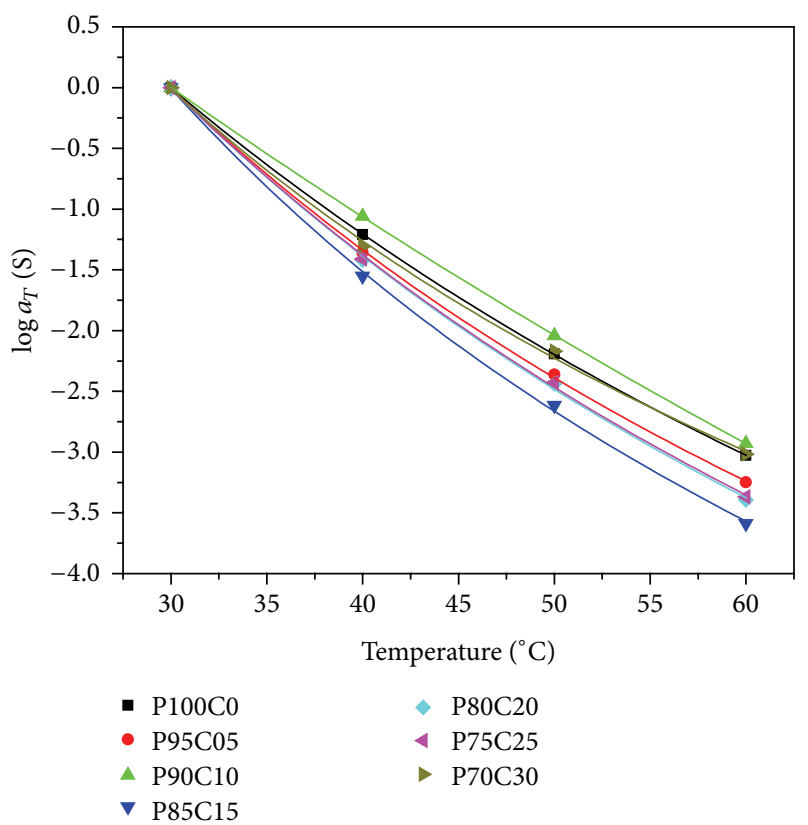

Figure 4: Temperature dependence of the shift factor, $\log a_{T}$. The solid lines in the graphs are fits according to WLF equation.

\subsection{Effect of Cellulose Loading on Percentage Strain Recovery.} The course of recovered \% creep strain as a function of time is also presented in Figure 1. While greater elasticity at higher temperature is recovered, larger permanent deformation of the elastic and viscous response is observed. The unrecovered strain at $60^{\circ} \mathrm{C}$ for composites containing $0,5,20,25$, and $30 \%$ cellulose is $0.42,0.44,0.47,0.5$, and $1.65 \%$. Moreover the curves also indicate that incorporation of cellulose improves the elastic recovery and increases the recovered strain remarkably.

3.3. Effect of Cellulose Loading on Creep Modulus of LDPE/Cellulose Composites. Figure 2 presents a plot of creep modulus against time for all composites at different temperatures.

It is clear from Figure 2 that creep modulus of all composites decreases with increase in temperature. This is attributed to higher deformation due to enhanced chain mobility at higher temperatures. Further, creep modulus (at the same temperature) increases with increase in cellulose loading. This implies that LDPE offers more resistance to creep when reinforced with cellulose. This difference in creep behaviour is attributed to the stiffening effect of cellulose majorly due to its higher crystallinity. The shape of different creep curves in Figure 3 is amenable to the well-known reduction scheme of time temperature superposition.

3.4. Long Time Creep of LDPE/Cellulose Composites. Time temperature superposition was performed to assess long term creep response of LDPE/cellulose composites. All the individual creep curves corresponding to different temperature levels were shifted along the logarithmic time axis to superpose to a master curve. A temperature of $30^{\circ} \mathrm{C}$ was chosen as the reference temperature because it is close to room temperature. The creep moduli master curves are shown in Figure 3.

The time temperature superposition treatment in this material has increased the range for predicting creep modulus change versus time by at least four decades over the range covered just by the raw experimental data (i.e., 700 to $10^{6} \mathrm{~s}$ ). The master curves show that creep modulus of composites with increasing cellulose content was higher than that of neat LDPE, which indicates the reinforcing effectiveness of cellulose. These findings also show that under a small stress the material entered into a viscoelastic state over an extremely long period of time, and in the viscoelastic state the cellulose plays a better role in the reinforcement of materials. The experimental shift factors were tested with WLF model (4).

The graph in Figure 4 shows that WLF equations adequately describe the temperature dependence of shift factors for LDPE and its composites. Hence the deformations depend on free volume. The fit parameters are shown in Table 1.

The values of $C_{1}$ and $C_{2}$ depend on the particular morphology or structure of a given material. From Table 2, the values of $C_{1}$ and $C_{2}$ have an inconsistent trend with cellulose loading indicating that cellulose has no effect on free volume with respect to temperature. Increase in $C_{1}$ and $C_{2}$ implies that a material is more crystalline or cross-linked as a result of increase in free volume and expansion with respect to temperature [11].

\section{Conclusions}

The reinforcing effect of cellulose in LDPE/cellulose composites is demonstrated by the increased creep performance of 
TABLE 2: WLF fit parameters for LDPE/cellulose composites.

\begin{tabular}{lccc}
\hline Sample & \multicolumn{3}{c}{ WLF parameters } \\
& $C_{1}$ & $C_{2}$ & $T_{o}(\mathrm{~K})$ \\
\hline P100C0 & $12.4 \pm 0.5$ & $92.7 \pm 4.4$ & $30.0 \pm 0.1$ \\
P95C05 & $11.3 \pm 1.4$ & $74.8 \pm 12.7$ & $29.9 \pm 0.2$ \\
P90C10 & $11.4 \pm 1.7$ & $69.1 \pm 17.2$ & $29.9 \pm 0.3$ \\
P85C15 & $11.2 \pm 2.0$ & $64.4 \pm 16.6$ & $30.0 \pm 0.4$ \\
P80C20 & $12.1 \pm 2.6$ & $78.1 \pm 22.8$ & $29.9 \pm 0.4$ \\
P75C25 & $12.0 \pm 2.3$ & $77.5 \pm 20.4$ & $30.0 \pm 0.4$ \\
P70C30 & $9.7 \pm 2.7$ & $67.3 \pm 25.9$ & $29.9 \pm 0.5$ \\
\hline
\end{tabular}

the blends with cellulose loading, particularly for the $\%$ cellulose content between $5 \%$ and $25 \%$. This was further confirmed by the increase in creep modulus with cellulose loading. The time temperature superposition (TTS) curves deviated from each other at longer times (higher temperatures). This indicates that temperature effect on viscoelastic response of such materials is much more significant than the effect of time. Smooth master curves were produced by TTS technique through horizontal shifts. This was useful in prediction of the long term creep for the composites.

\section{Acknowledgment}

The authors are grateful to the Physics Department of Kenyatta University for providing facilities to carry out creep measurement process.

\section{References}

[1] Y. Jia, K. Peng, G. Xing-Long, and Z. Zhong, "Creep and recovery of polypropylene/carbon nanotube composites," International Journal of Plasticity, vol. 10, no. 10160, pp. 1-12, 2011.

[2] N. G. Mc Crum, C. P. Buckley, and C. B. Bucknall, Principles of Polymer Engineering, Oxford Science, New York, NY, USA, 1997.

[3] A. S. Ali, Long term prediction of Polyethylene nanocomposites [Ph.D. thesis], University of Texas, Austin, Tex, USA, 2008.

[4] P. K. Sastry, D. Satyaranayana, and D. Rao, "Accelerated and environmental weathering studies on polyethylene-starch blend films," Journal of Applied Polymer Science, vol. 70, pp. 2251-2257, 1998.

[5] A. C. Albertsson, S. O. Andersson, and S. Karlsson, "The mechanism of biodegradation of polyethylene," Polymer Degradation and Stability, vol. 18, no. 1, pp. 73-87, 1987.

[6] M. Rutkowska, A. Heimowska, K. Krasowska, and H. Janik, "Biodegradability of polyethylene starch blends in sea water," Polish Journal of Environmental Studies, vol. 11, no. 3, pp. 267271, 2002.

[7] P. B. Shah, S. Bandopadhyay, and J. R. Bellare, "Environmentally degradable starch filled low density polyethylene," Polymer Degradation and Stability, vol. 47, no. 2, pp. 165-173, 1995.

[8] D. Bikiaris and C. Panayiotou, "LDPE/starch blends compatibilized with PE-g-MA copolymers," Journal of Applied Polymer Science, vol. 70, no. 8, pp. 1503-1521, 1998.

[9] T. Behjat, R. Russly, C. Luqman, A. Nor, and A. Yus, "Thermal properties of low density polyethylene-filled kenaf cellulose composites," European Journal of Scientific Research, vol. 32, no. 2, pp. 223-230, 2009.
[10] N. E. Marcovich and M. A. Villar, "Thermal and mechanical characterization of linear low-density polyethylene/wood flour composites," Journal of Applied Polymer Science, vol. 90, no. 10, pp. 2775-2784, 2003.

[11] L. Champion, J. F. Gerard, J.-P. Planche, D. Martin, and D. Anderson, "Low temperature fracture properties of polymermodified asphalts relationships with the morphology," Journal of Materials Science, vol. 36, no. 2, pp. 451-460, 2001. 

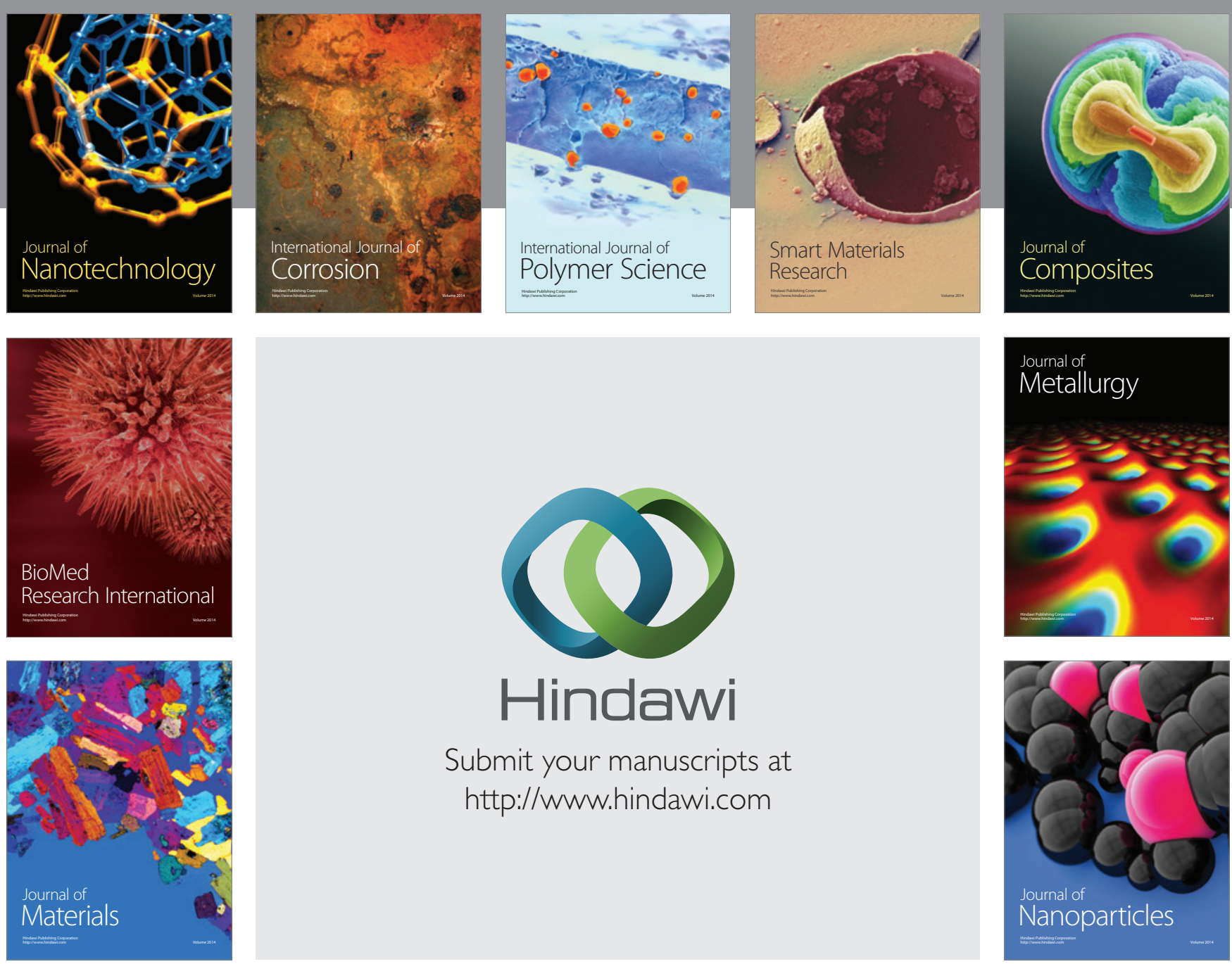

Submit your manuscripts at http://www.hindawi.com
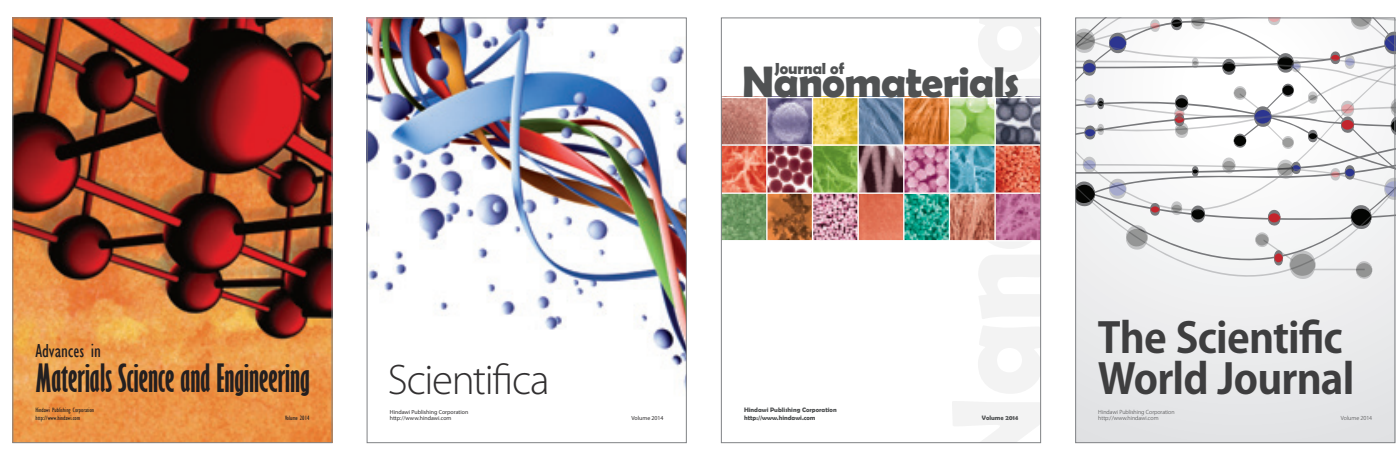

\section{The Scientific World Journal}
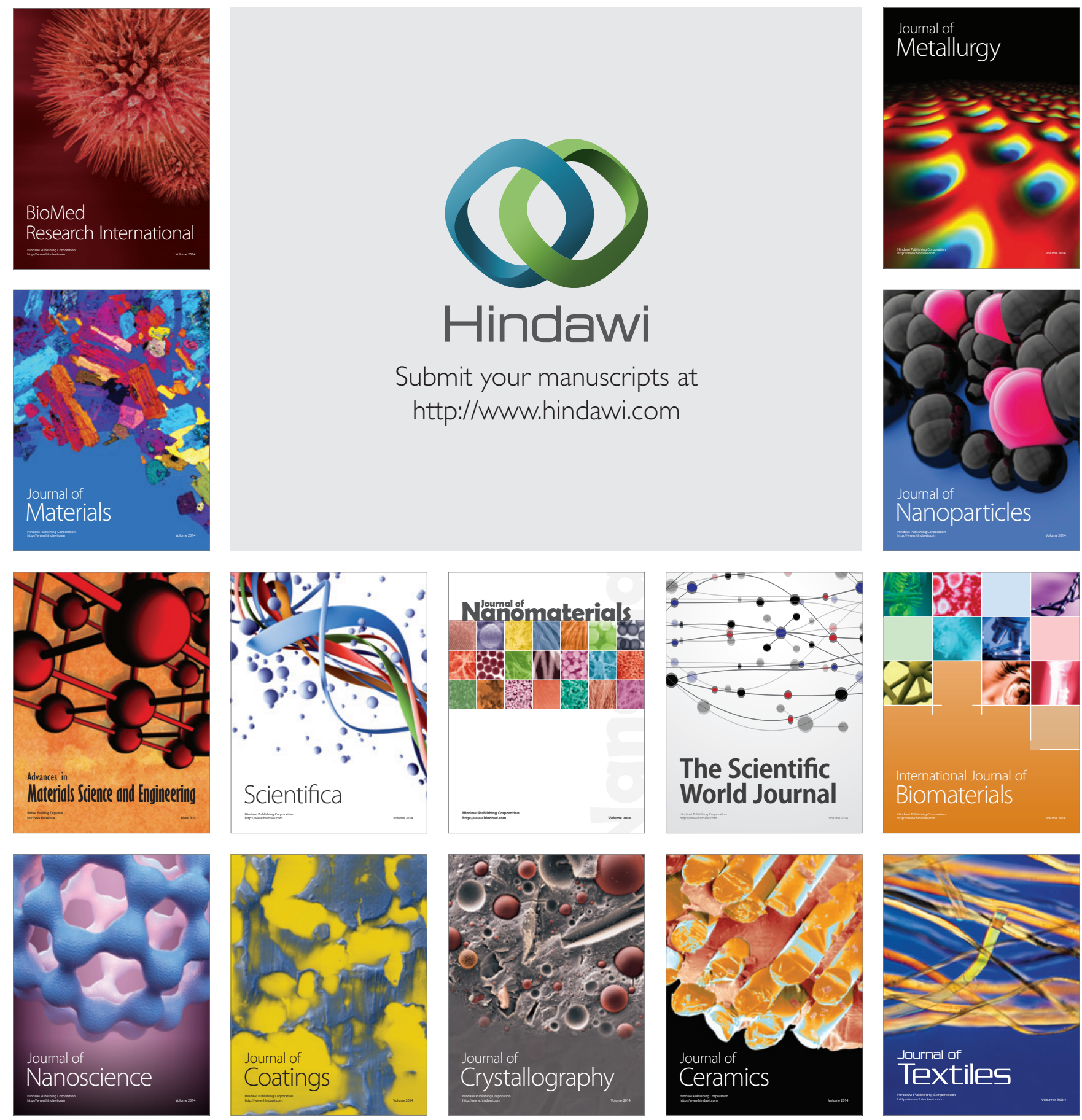